\title{
An Investigation of Bend Connection Effect on the Finite Amplitude Oscillation in Circular Ducts
}

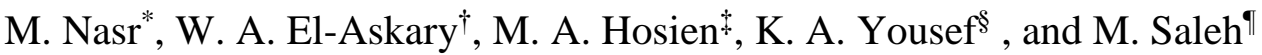

\begin{abstract}
This paper presents an experimental and theoretical study of finite amplitude oscillations in circular ducts ended with/without bend with connections. The acoustic oscillations are created by reciprocating piston at the closed end of the circular duct while the other end is left free end or it is fitted with constant cross section area bend with different turning angles. Three different turning angles for bends of 450, 900, and 1350 degrees were used for experimental study. The pressure time histories along the duct were recorded at three different axial locations using a capacitance pressure transducer connected to a data acquisition system and DAQ VIEW software. The results showed that, the bend angle has a significant effect on wave deformation inside the duct. Also, it is observed that, close to the piston, the free end duct (duct without bending) has a larger acoustic wave amplitude than the same duct fitted with the bend and the vice versa for the duct close to its exit exactly before the attached bend entrance. Also, the amplitude of the wave in the duct close to the piston increases with rising the bend angles from 450 to 1350 , while it decreases close to the duct exit exactly before the bend entrance with increasing the bend angle. That is due to the wave reflections from the bend at the duct exit and wave interaction between different wave phases at the duct exit. Two different piston reciprocating speeds have been used and the results are compared for the different bend turning angles. The numerical simulation and analytical solution are compared with the experimental results for qualitative validation. It is noticed that the experimental results were in agreement with the numerical and analytical results within an accepted error. Also, fast Fourier transform is performed for the experimental results and higher harmonics are noticed for duct fitted with bends at its exit. These higher harmonics are significantly noticed for duct fitted with 1350 bend.
\end{abstract}

Keywords: Acoustic wave, circular duct, bend angle, CFD, FFT.

\section{Nomenclature}

bn Wave number

Et Total energy, $\mathrm{J} / \mathrm{kg}$

FFT Fast Fourier Transform

Professor and Previous Dean Faculty of Engineering, Menoufia University. Current: Alexandria Higher Institute for Engineering and Technology (AHIET).

$\dagger$ Professor and Head of Mechanical Power Engineering Dept. Faculty of Engineering, Menoufia University.

* Assistant Professor at Mechanical Power Engineering Dept. Faculty of Engineering, Menoufia University.

$\S$ Lecturer at Mechanical Power Engineering Dept. Faculty of Engineering, Menoufia University.

II MSc research student at Mechanical Power Engineering Dept. Faculty of Engineering, Menoufia University, Egypt 


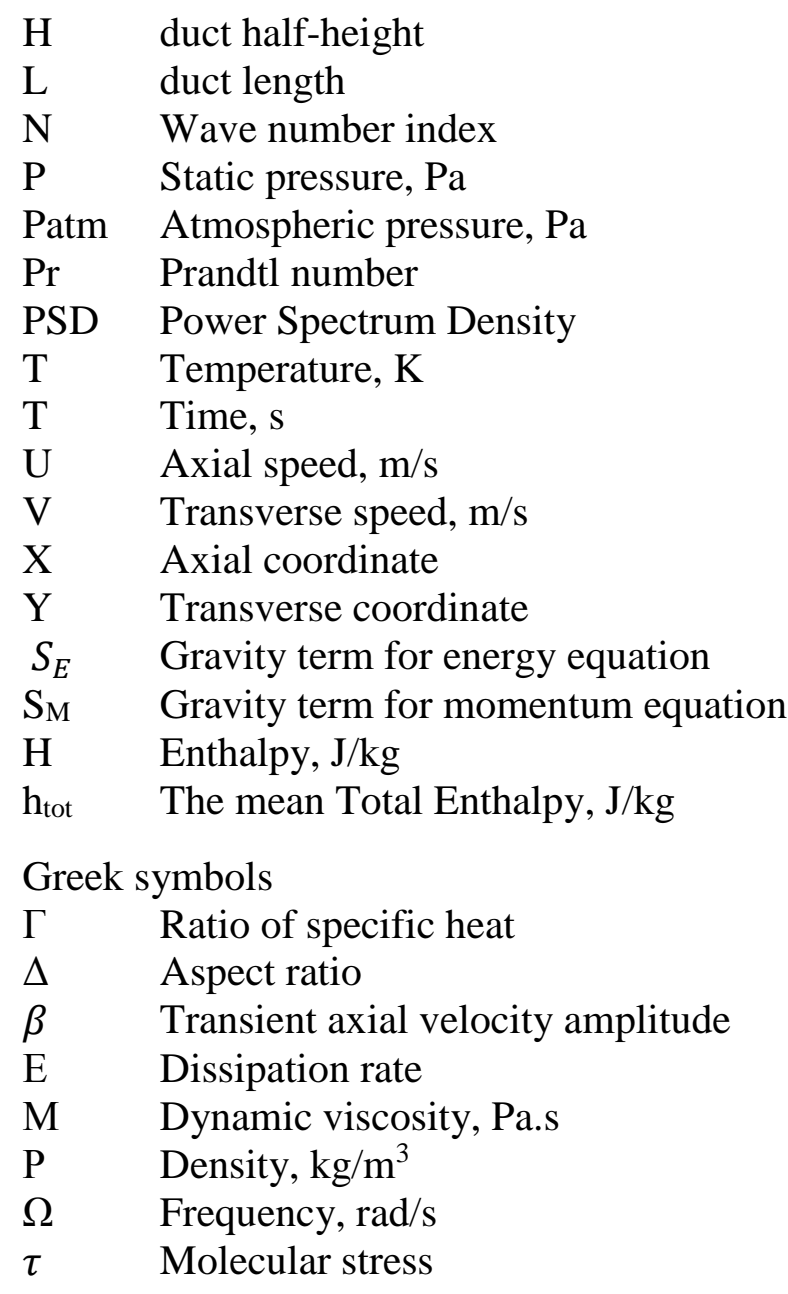

\section{Introduction}

The acoustic wave in ducts can be excited by an oscillating piston at the closed end while bends with different turning angles are fitted alternatively at the duct exit. The exit boundary has a sensible effect on the generated acoustic waves in ducts and this effect has many applications such as, pipe line system, intake and exhaust system, ventilation, conditioning system, pneumatic conveying systems, and the body system of human (blood flow within veins and arteries) [1]. The theory of gas oscillations in ducts is one of the most interesting problems of hydrodynamic acoustics. High-intensity oscillations of a gas are usually excited by a piston which harmonically oscillates at one end of the duct. Oscillations in such systems are accompanied by number of interesting effects [2]. In the design and operation of an airconditioning duct system and a pipe network, both the stability and the efficiency of the entire plant are important. The turbulent pulsating flow is a great help to advance not only most suitable design of the exhaust pipelines, but also capability and efficiency of the reciprocating engine. At the end of the nineteenth century, the flows in curved tubes were introduced to the field of fluid engineering, but in the 1920's, theoretical and analytical research was mainly conducted for cases of small-curvature radius. Researchers began to study pulsating flows with the development of both analytical and experimental methods, especially for the unsteady flows, which are very complicated phenomena. The study of unsteady flows in the curved ducts was mainly undertaken after 1970 [3]

Evant [1] presented an experimental study for nonlinear acrostic oscillations near the resonance for closed and open tubes. They found that for closed tube when shock waves occur, the effect of increasing orifice area is not only weakening the shocks but thicken them also. In open tube, the oscillations at resonance have significant large amplitude. Galiullin et al. [2] presented 
analytical theory of resonant oscillations of gas in an open-end tube. They concluded that the analytical results are in reasonable agreement with experimental data obtained by other experiments.

Selim and Nasr [4] discussed the effect of adding divergent, convergent and convergentdivergent nozzles to the exit of a constant cross-section duct. They concluded that, when adding convergent area to the end of duct, the amplitude of wave decreases and the amplitude of wave decreases with diminishing the exit diameter. When adding a divergent area at the duct exit, the amplitude of wave increases and the amplitude of wave increases with magnifying the exit diameter. When adding convergent-divergent area, the amplitude of wave decreases beside the piston but near to the end of duct it decreases greater than for the convergent area. Nasr et al. [5] studied the effect of the exit connections on the generated acoustic inside a square duct. They presented the effect of adding convergent and convergent-divergent nozzles at the duct exit. They concluded that the acoustic flow field in duct is highly affected by the exit connection. Jinsuo and Zhao [6] discussed the flow in helical circular pipe using perturbation method. They described that, the behavior of the flow in a helical pipe is dominated by three parameters, curvature, axial pressure and torsion. For the same pressure gradient, the volume flux in a helical pipe is larger than that in a straight pipe.

Dequand et al. [7] discussed the acoustic response for $90^{\circ}$ sharp bends. The bends which were considered are sharp $90^{\circ}$ in near edge and rounded or sharp out corner connected with a pipe in two-dimensional square cross-sectional area or three-dimensional acicular area. Numerical method was used with the non- liner Euler equations for two dimensional inviscid compressible flows. They briefed that, in a $90^{\circ}$ bend with sharp inner edge and sharp outer edge, two dimensional numerical simulations accurately predict the available two-dimensional experimental data. For a $90^{\circ}$ sharp bend with a rounded outer corner the simulation accurately predicts the available two dimensional experimental data. The acoustical response of a sharp bend with a rounded outer corner in pipes with circular cross section is close to that of a bend with a sharp inner edge and a sharp outer corner.

Rienstra and Hirschberg [8] discussed the acoustic wave in a duct of constant cross section. The reduced wave (or Helmholtz) equation was solved by means of a series expansion in a particular family of solutions, called modes. They are related to the Eigen solutions of the twodimensional Laplace operator acting on a cross section. They concluded that, if the duct cross section is circular or rectangular and the boundary condition is uniform everywhere, the solutions of the eigenvalue problem are relatively simple and may be found by separation of variables. Huang et al [9] discussed the use of ultrasonic guided waves that generated by electromagnetic acoustic transducer to inspect the crack in gas pipe line system. They concluded that the circumferential guided wave in the pipe is the ultrasonic guided wave that is used in the detection of cracks in the pipe. Uz and Tamer [10] investigated numerically the acoustic fatigue and dynamic response of composite panels under acoustic excitation. They found that the critical element identification of the model regarding response can be considered as pre-analysis performed to predict the element with maximum probabilistic response, i.e. root mean square strain. The highest rms micro strain on the selected critical element is then obtained as postprocess.

The objective of the present work is study experimentally and theoretically the finite amplitude oscillations in an open constant area circular duct with free end. Also, it discusses the effect of adding bends of different tuning angles fitted at its exit on the wave pattern inside the circular duct. It presents the effect of bend angle (the angle between the main duct axis and the bend exit axis) and imposed frequency on the acoustic wave generation in the duct at three different axial locations. 


\section{Experimental Set-up}

The schematic view of the experimental apparatus with instruments to perform the experimental measurements is illustrated in Fig. 1. The experimental apparatus consists of the following parts: an oscillating piston [motor cycle piston cylinder system of $5.1 \mathrm{~cm}$ diameter and $5.08 \mathrm{~cm}$ stroke]. This piston is driven by an electrical AC motor of $2800 \mathrm{rpm}, 3 \mathrm{HP}$, one phase electrical input and suitable for variable speed through a pulley-belt system. The number of revolutions of the AC motor can be changed by a voltage regulator. The variable speed piston oscillates at one end of the $5.1 \mathrm{~cm}$ test circular duct of $96.7 \mathrm{~cm}$ length and the other end of the duct is opened to atmosphere. Three bends with three turning angles of $45^{\circ}, 90^{\circ}$ and $135^{\circ}$ degrees are changeably added to the open end of the circular cross-sectional area channel. Wall pressuretime histories are recorded at three axial; locations along the channel, $13 \mathrm{~cm}$ (point 1 , $\mathrm{X} / \mathrm{L}=0.134$ ), $60 \mathrm{~cm}$ (point 2, $\mathrm{X} / \mathrm{L}=0.620$ ) and $91 \mathrm{~cm}$ (point 3, $\mathrm{X} / \mathrm{L}=0.941$ ) from the piston TDC. The pressure histories are measured using pressure transducers of type OMEGADYNE INC, model no px02c1-100GL, with the range of 0 to 100 PSI and accuracy of $0.1000 \pm \%$ FS [11] . The pressure transducers are connected to a data acquisition system DAS MODEL, omega 3005 and computer through a DAQVIEW software [12]. The experimental results are recorded and stored at the three different axial locations at the same time and two forcing frequencies of 515.27 and $471 \mathrm{rad} / \mathrm{s}$. The piston forcing frequency is measured by using Tachometer.

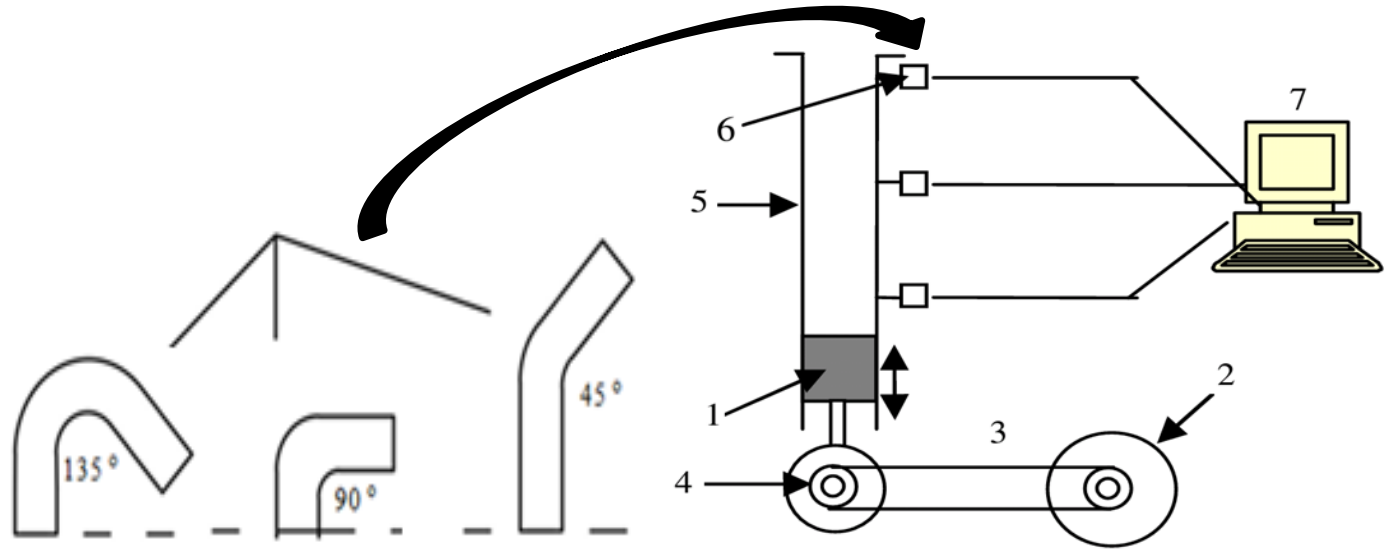

1-Reciprocating piston, 2- Electrical motor, 3-Belt, 4-pulley, 5- Duct, 6- Pressure transducer, 7- Computer and DAS.

Fig. 1. Experimental test rig with the three different bends

\section{Mathematical Model}

In the present work, the unsteady Reynolds averaged Navier Stokes equations in the form of compressible flow are solved. Because of the presence of compressibility and temperature variations the energy equation and gas low are also included. For turbulence effects, the standard $\mathrm{k}-\varepsilon$ model [13] is adopted and implemented in ANSYS-FLUENT in the present work. The Reynolds averaged Navier Stokes and energy equations as well as the turbulence model equations are solved using the finite volume based code of ANSYS 16. The numerical computations of the flow behavior is carried out for unsteady three-dimensional flow. Second order upwind condition and first order implicit time marching schemes are used. The considered time step size is 0.001 second. A grid dependence study is performed based on that performed by Nasr et al [5]. Velocity inlet using UDF (User Defined Functions) is used to introduce the acoustic wave generated at the duct inlet. The inlet velocity is compiled using $\mathrm{C}$ language. The temperature is considered to be uniform and equal to $300 \mathrm{k}$. The duct with/without bend freely discharge to atmosphere having an atmospheric pressure at its exit. The duct wall has a constant temperature of $300 \mathrm{~K}$ and the duct exit is considered as pressure outlet.

Reynolds Averaged Navier-Stokes (RANS) Equations [14]: 
$U_{i=} \bar{U}_{i}+u_{i}$

The averaged component is given by:

$$
\overline{\mathrm{U}}_{\mathrm{i}}=\frac{1}{\Delta \mathrm{t}} \int_{\mathrm{t}}^{\mathrm{t}+\Delta \mathrm{t}} \mathrm{U}_{\mathrm{i}} \mathrm{dt}
$$

Substituting the averaged quantities into the original transport equations results in the Reynolds averaged equations given below. In the following equations, the bar is dropped for averaged quantities, except for products of fluctuating quantities.

Continuity equation:

$$
\frac{\partial \rho}{\partial t}+\frac{\partial}{\partial x_{j}}\left(\rho U_{j}\right)=0
$$

Momentum equation:

$\frac{\partial \rho U_{i}}{\partial t}+\frac{\partial}{\partial x_{j}}\left(\rho U_{i} U_{j}\right)=-\frac{\partial P}{\partial x_{i}}+\frac{\partial}{\partial x_{j}}\left(\tau_{i j}-\rho \overline{u_{\imath} u_{\jmath}}\right)+S_{M}$

where $\tau$ is the molecular stress tensor (including both normal and shear components of the stress.

Energy equation:

$\frac{\partial \rho h_{t o t}}{\partial t}-\frac{\partial P}{\partial t}+\frac{\partial}{\partial x_{j}}\left(\rho U_{j} h_{t o t}\right)=\frac{\partial}{\partial x_{j}}\left(\lambda \frac{\partial T}{\partial x_{j}}-\rho \overline{U_{l} h}\right)+\frac{\partial}{\partial x_{j}}\left(U_{i}\left(\tau_{i j}-\rho \overline{u_{l} u_{J}}\right)+S_{E}\right.$

The mean Total Enthalpy is given by:

$h_{\text {tot }}=h+\frac{1}{2} U_{i} U_{i}+k$ and $k=\frac{1}{2} \overline{u_{\imath}^{2}}$

The Standard k- $\varepsilon$ model equations can be written as follows [14]:

$$
\begin{aligned}
& \frac{\partial}{\partial t}(\rho k)+\frac{\partial}{\partial x_{i}}\left(\rho k U_{i}\right)=\frac{\partial}{\partial x_{j}}\left(\left(\mu+\frac{\mu_{t}}{\sigma_{k}}\right) \frac{\partial k}{\partial x_{j}}\right)+G_{K}+G_{b}-\rho \varepsilon-Y_{M}+S_{K} \\
& \frac{\partial}{\partial t}(\rho \varepsilon)+\frac{\partial}{\partial x_{i}}\left(\rho \varepsilon U_{i}\right)=\frac{\partial}{\partial x_{j}}\left(\left(\mu+\frac{\mu_{t}}{\sigma_{\varepsilon}}\right) \frac{\partial \varepsilon}{\partial x_{j}}\right)+C_{1 \varepsilon} \frac{\varepsilon}{K}\left(G_{K}+C_{3 \varepsilon} G_{b}\right)-C_{2 \varepsilon} \rho \frac{\varepsilon^{2}}{K}+S_{\varepsilon}
\end{aligned}
$$

In these equations, $G_{K}$ represents the generation of turbulence kinetic energy due to the mean velocity gradients. $G_{b}$ is the generation of turbulence kinetic energy due to buoyancy, $Y_{M}$ represents the contribution of the fluctuating dilatation in compressible turbulence to the overall dissipation rate. $C_{1 \varepsilon}, C_{2 \varepsilon}$, and $C_{3 \varepsilon}$ are constants. $\sigma_{k}$ and $\sigma_{\varepsilon}$ are Prandtl numbers for $k$ and $\varepsilon$. $S_{K}$ and $S_{\varepsilon}$ are user defined source terms.

\section{Analytical Solution}

Analytical solution is simple and it uses more simplifying assumptions compared with the numerical solution. However, analytical solution is suitable for certain limits of the flow Parameters. Below is analytical solution for pure acoustic oscillations for duct without bend as shown in the layout above Figure 2. End wall disturbance is considered at the duct head end 
while the other end is open to atmosphere. The analytical approach is based on the reduced form of the Navier-Stokes equations.

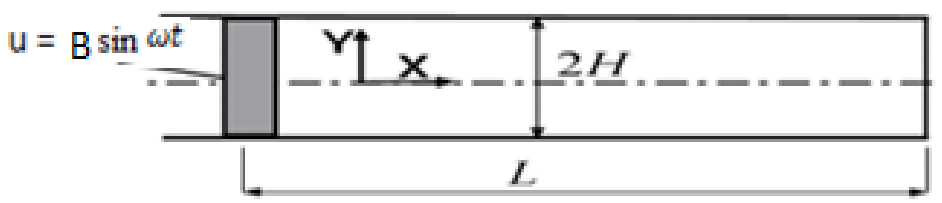

Fig. 2. Reciprocating piston oscillation in the circular duct

The one-dimensional wave equation is:

$\frac{\partial^{2} U}{\partial t^{2}}=\frac{\partial^{2} U}{\partial x^{2}}$

With the boundary and initial conditions,

at $\mathrm{t}=0$ then $U=0$ and $\frac{\partial U}{\partial t}=0$

at $\quad \mathrm{x}=0 \quad$ then $U=\beta \sin (w t)$

at $\mathrm{x}=1$ then $\frac{\partial U}{\partial x}=0$

Therefore, the non-resonance acoustic solution is [8].

$$
U(x, t)=\beta \sin \omega t+\sum_{n=0}^{\infty} 2 \frac{\beta \omega}{b_{n}^{2}-\omega^{2}}\left(\frac{\omega}{b_{n}^{2}} \sin \omega t-\sin b_{n} t\right) \sin b_{n} x
$$

where for $b_{n=}\left(n+\frac{1}{2}\right)$ for $\omega \neq b_{n}$ the pressure $P_{o}$ is found using the following equation.

$$
\frac{\partial u(x, t)}{\partial t}=-\frac{1}{\gamma} \frac{\partial p(x, t)}{\partial x}
$$

with the boundary conditions at $\mathrm{x}=1$ reading $\mathrm{p}=1$

$$
p(x, t)=\beta \gamma \omega(x-1) \cos \omega t-\sum_{n=0}^{\infty} \frac{2 \beta \omega}{b_{n}^{2}}\left(\cos \omega t-\cos b_{n} t\right) \cos b_{n} x .
$$

and the thermodynamics variables are:

$$
\begin{aligned}
T & =\frac{\gamma-1}{\gamma} P \\
\rho & =\frac{1}{\gamma} P
\end{aligned}
$$

The solution for resonance case can be found as, [8]

$u(x, t)=\beta \sin \omega t-\left\{\frac{1}{b_{n}} \sin \left(b_{n} t\right)+t \cos \left(b_{n} t\right)\right\} \sin$
$p(x, t)=\gamma \beta \omega \cos (\omega t)(x-1)-\gamma\left\{2 \cos \left(b_{n} t\right)-b_{n} t \sin \left(b_{n} t\right)\right\} \cos \left(b_{n} x\right)^{\prime}$

where $b_{n}=\omega$ and $\varepsilon$ represent the wave amplitude. 


\section{Results and Discussions}

The current work is devoted to examine the time-dependent flow field in an open duct freely discharge to atmosphere with/without bend installed at its exit. The present work is objected to describe the effect of installing bend with different turning angles of $45^{\circ}, 90^{\circ}$ and $135^{\circ}$ at the duct exit on the complex wave pattern inside that duct. In the present study, the results describe the comparison between free end duct and duct fitted with three bend turning angles. Figure 3 presents the theoretical and experimental axial pressure distribution comparison for free end duct. It is noticed that, the static pressure reaches its maximum value at the closed head end of the channel $(\mathrm{X} / \mathrm{L}=0)$ and it gradually decreases toward the duct exit. It is attributed to the accumulated acoustics wave on the reciprocating closed head end. The comparison between the numerical, experimental and analytical results shows reasonable agreement.

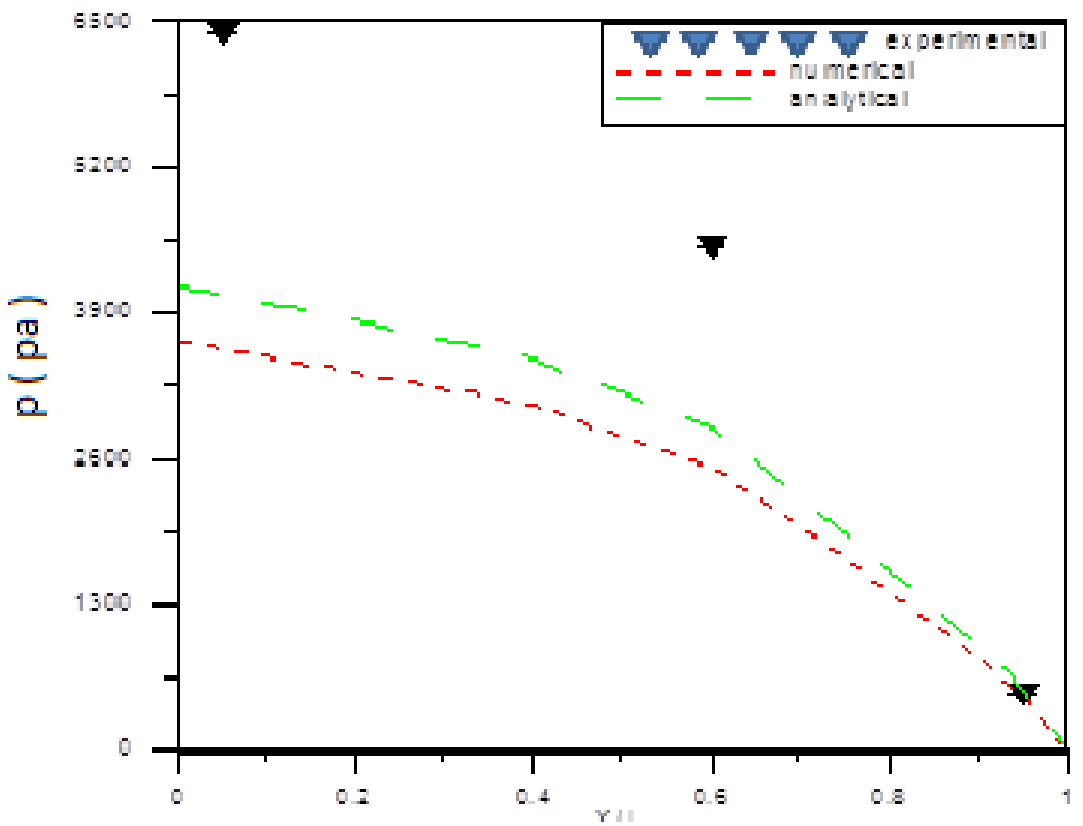

Fig. 3. Static pressure distribution along the duct.

The main purpose of this set is to describe the effect of forced frequency, axial location and the exit geometry on the generated acoustic field inside the interior cavity of the duct. Figures 4 and 5 represent a comparison of the experimental, numerical and analytical pressure time history at $\omega=515.27 \mathrm{rad} / \mathrm{s}$ and $\mathrm{X} / \mathrm{L}=0.134$ and 0.62 . This comparison shows under estimation for the numerical results but it represents a qualitative agreement. The pressure amplitude difference may be attributed to the assumptions used in the numerical solution. Figures 6 and 7 show the effect of installing $45^{\circ}$ bend at the same operational conditions at $\mathrm{X} / \mathrm{L}=0.134$ and 0.62 . The numerical results show over estimation in case of $45^{0}$ bend comparison. This may be attributed to the effect of reflected wave interaction from the bend at the duct exit. This interaction may damp out the acoustic amplitude in the numerical solution in $45^{\circ}$ bend over the free end duct which results in a good comparison in $45^{\circ}$ bend. Also, it is noticed that, existence of the $45^{\circ}$ bend at the end of the duct decreases the pressure amplitude compared with free end duct.

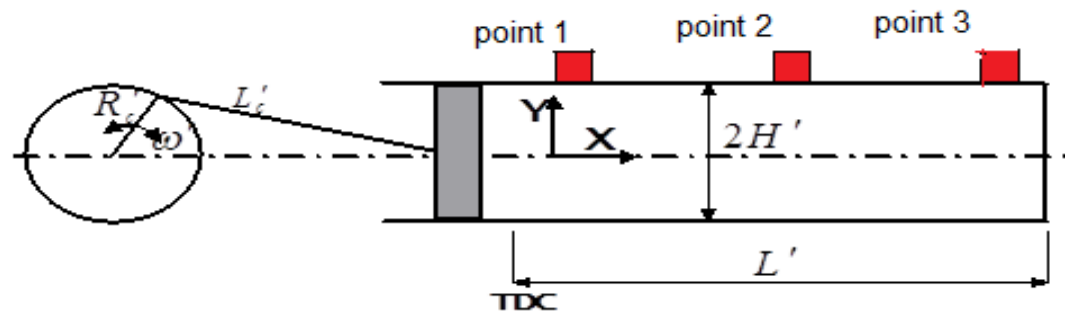




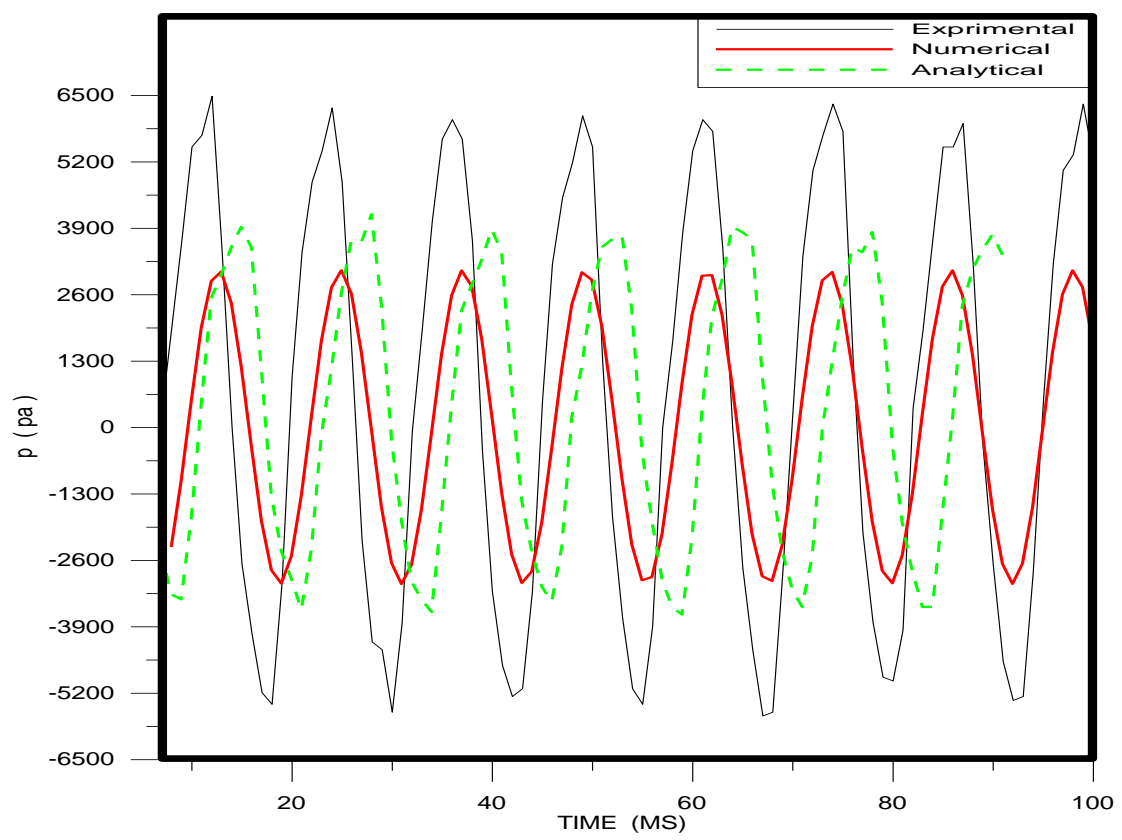

Fig. 4. Dimensional pressure time history for free end duct at $\omega=515.27 \mathrm{rad} / \mathrm{s}, \beta=0.0508$, and $X / L=0.134$.

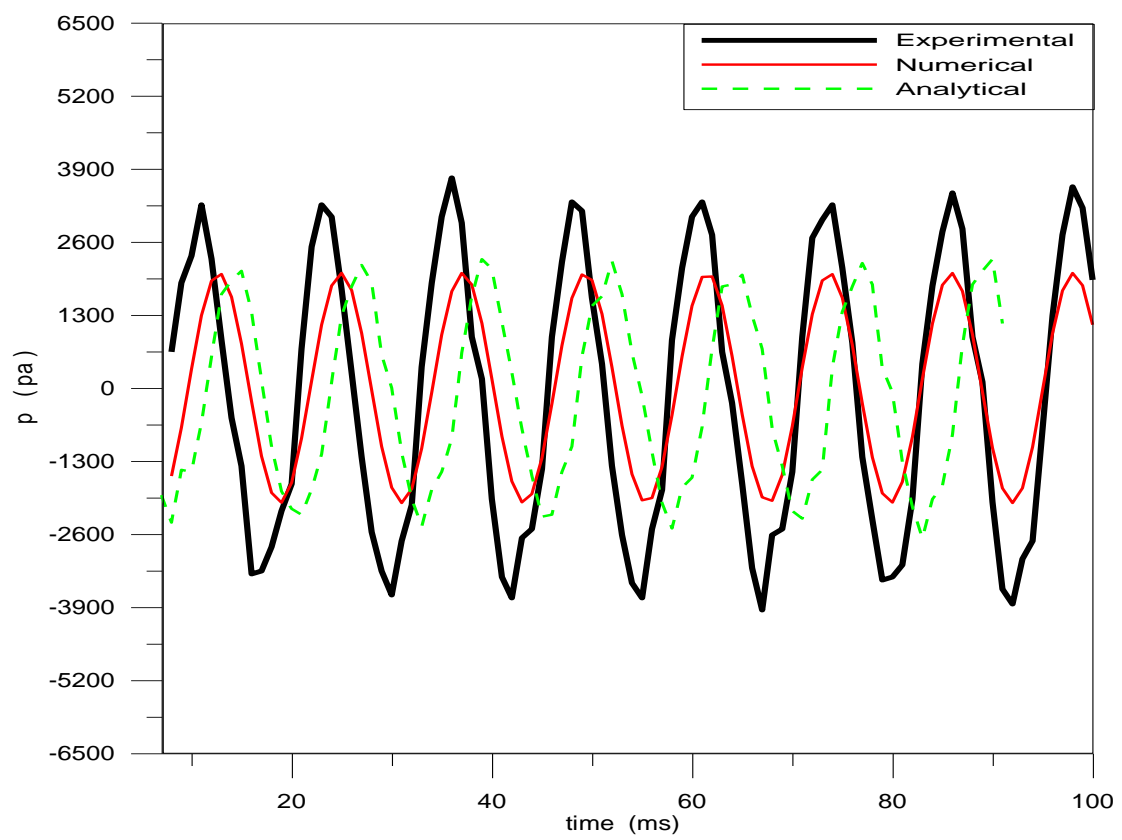

Fig. 5. Dimensional pressure-time history for free end duct $\omega=515.27 \mathrm{rad} / \mathrm{s}, \beta=0.0508$, and $X / L=0.62$ 


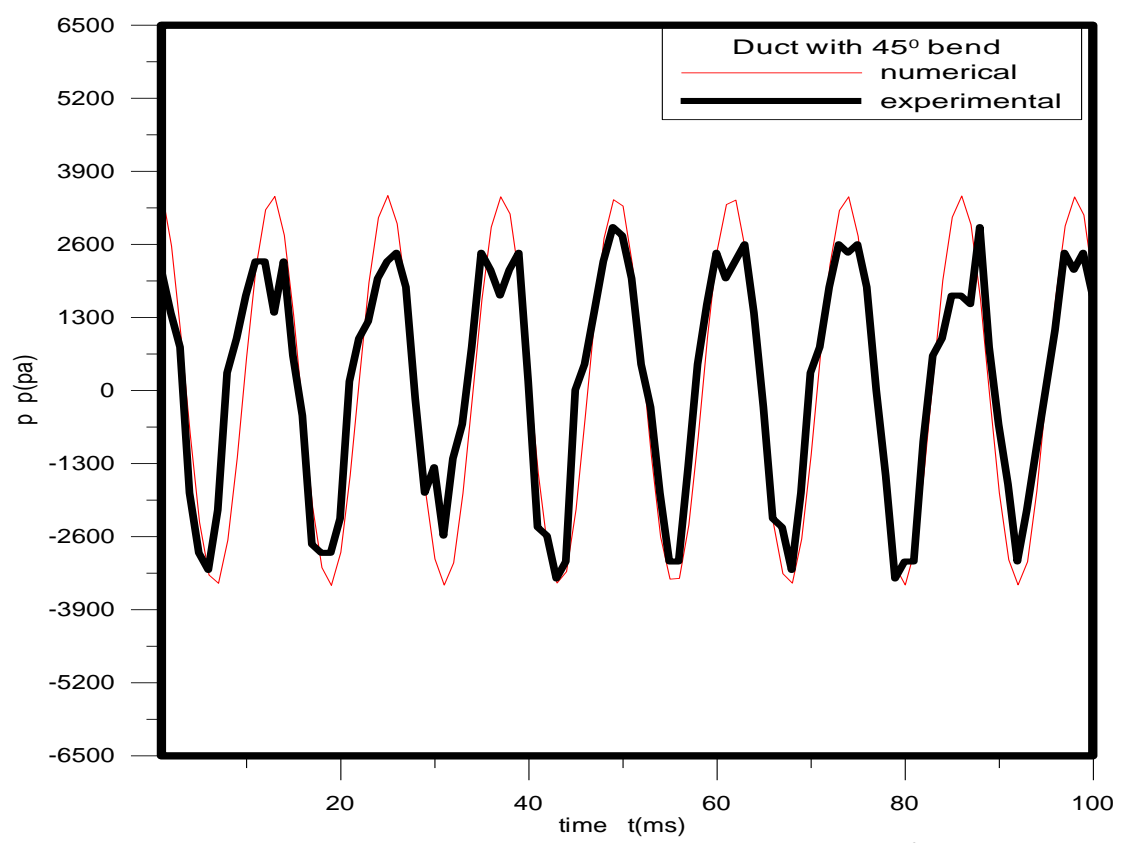

Fig. 6. Dimensional pressure-time history for $45^{\circ}$ bend at $\omega=\mathbf{5 1 5 . 2 7} \mathrm{rad} / \mathrm{s}, \beta=0.0508$, and $X / L=0.134$.

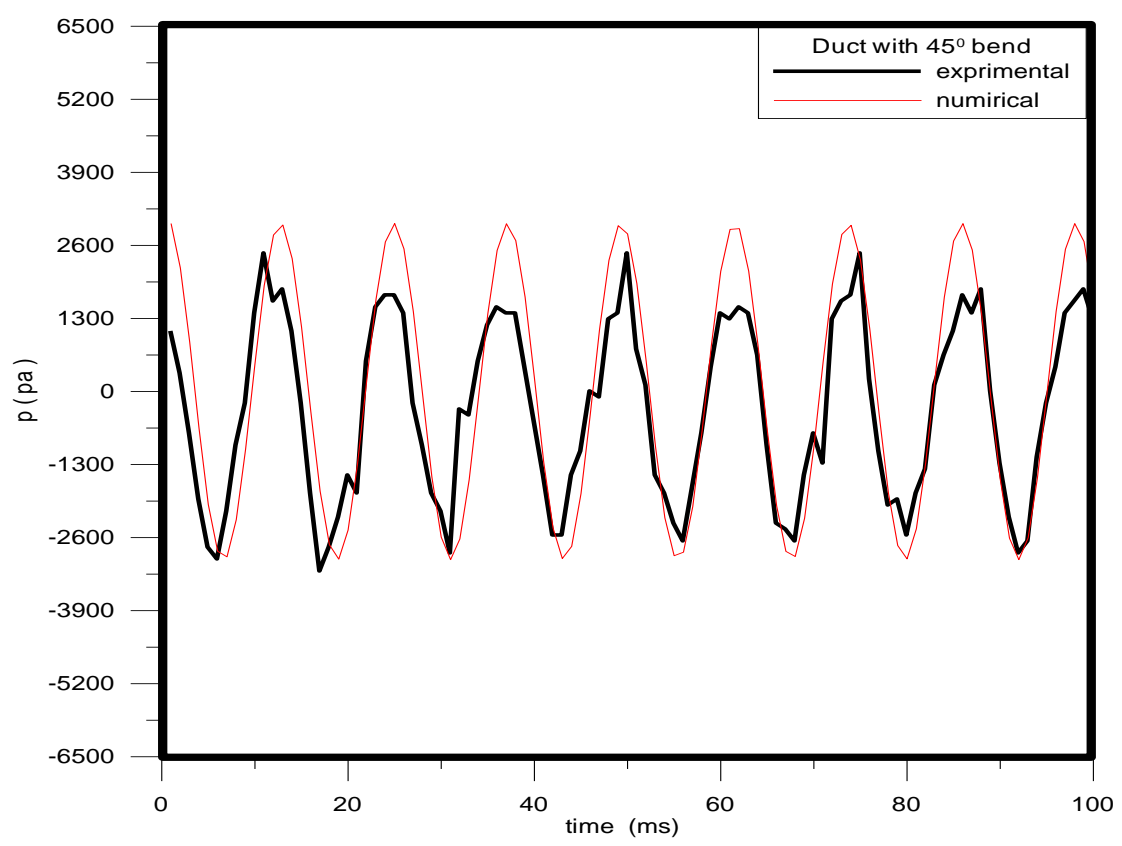

Fig. 7. Dimensional pressure time history for duct with $45^{\circ}$ bend at $\omega=\mathbf{5 1 5 . 2 7} \mathrm{rad} / \mathrm{s}, \beta=\mathbf{0 . 0 5 0 8}$, and $X / L=0.62$

Figures 8 and 9 illustrate the pressure time history at $\mathrm{X} / \mathrm{L}=0.134$ and 0.941 at forced frequencies of $471 \mathrm{rad} / \mathrm{s}$ and $515.27 \mathrm{rad} / \mathrm{s}$ for free end duct . It shows that the pressure amplitude increases when the rotational speed goes up due to raising the forcing wave amplitude at the piston surface. Also, it is noticed small phase difference between both frequencies due to wave number difference. The effect of axial location on the pressure time history with the same operational conditions is shown in Fig. 9 at $\mathrm{X} / \mathrm{L}=0.941$ compared to Fig.8. 


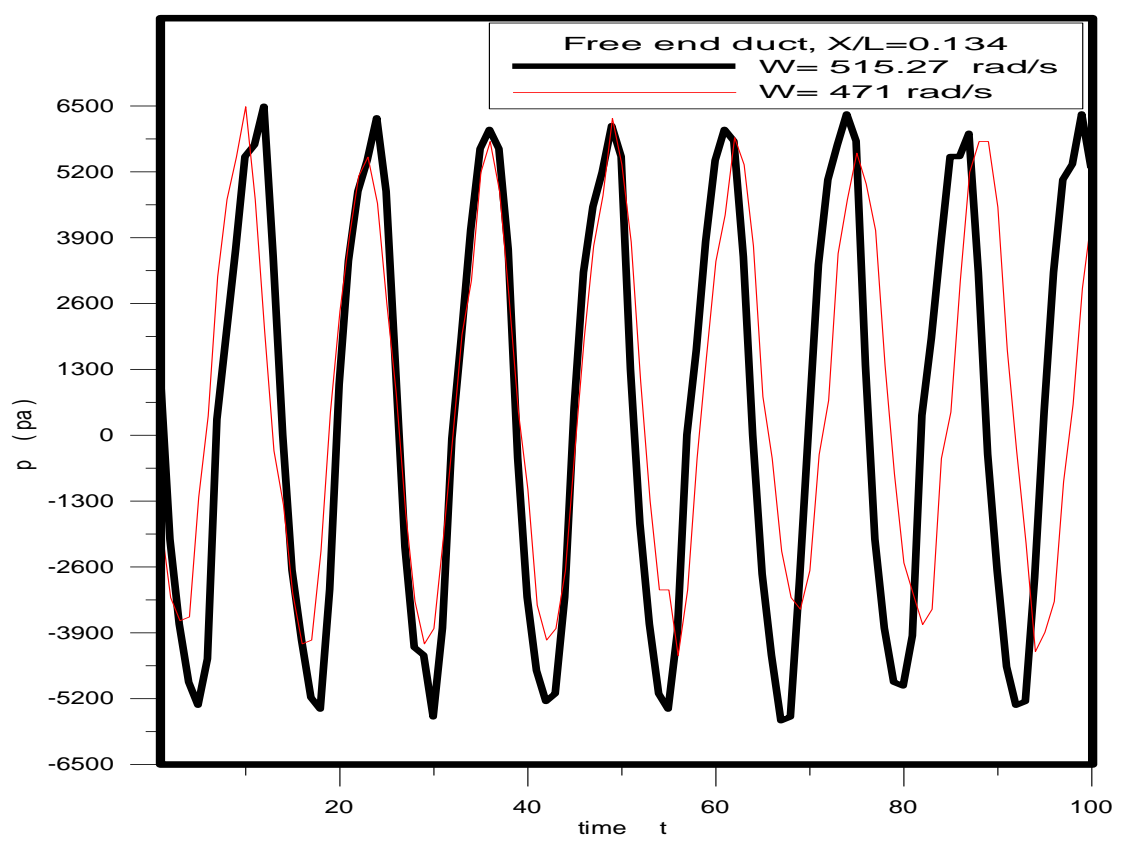

Fig. 8. Dimensional pressure time history for the free end duct at $\omega=515.27, \omega=471$, and $X / L=0.134$.

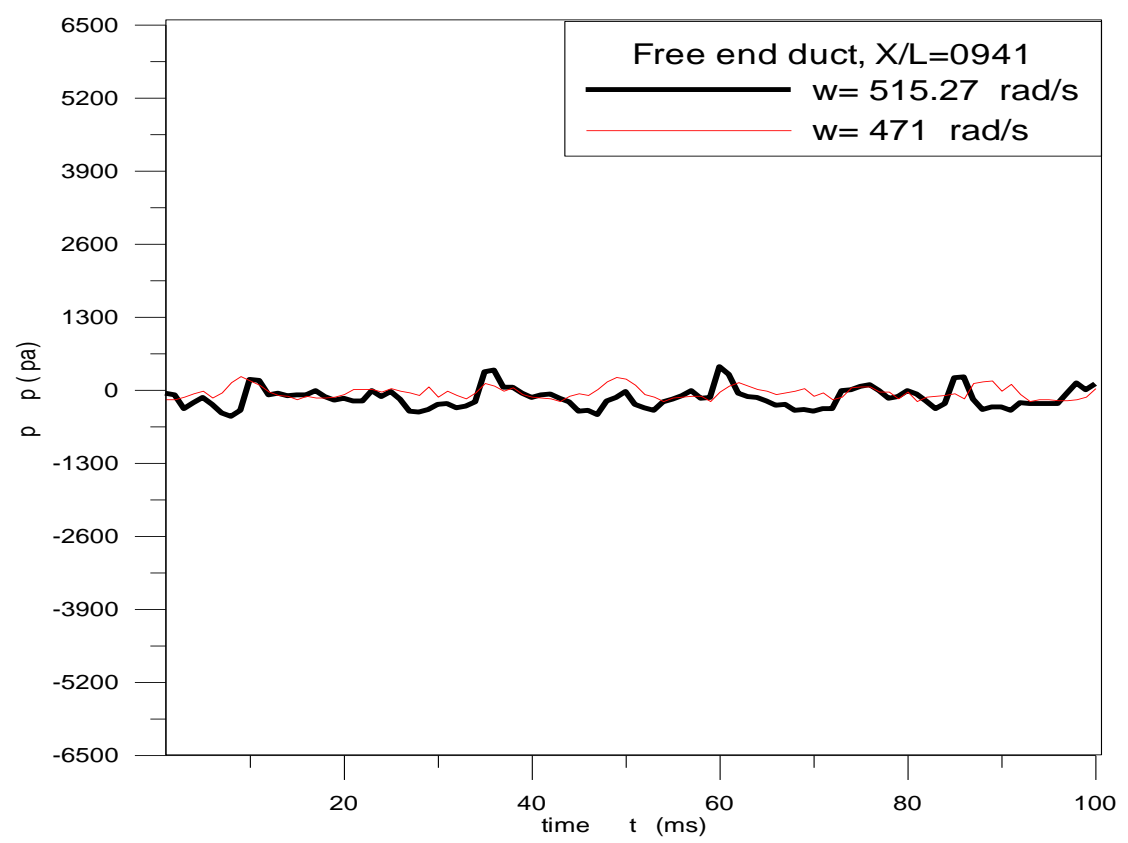

Fig. 9. Dimensional pressure time history for the free end duct at $\omega=515.27$ and $471 \mathrm{rad} / \mathrm{s}$ and $X / L=0.941$.

Figures 10 and 11 illustrate the pressure time history at $\mathrm{X} / \mathrm{L}=0.134$ and 0.941 at two forcing frequencies of $\omega=471$ and $=515.27 \mathrm{rad} / \mathrm{s}$ for duct with $45^{\circ}$ bend. It can be seen that, small noticeable amplitude and phase differences between the two forcing frequencies. This may be attributed to the wave reflected in case of duct with $45^{0}$ bend. Also, higher harmonics can be shown in both frequencies in this case. Large damping for the pressure amplitude is shown in Fig. 11 due to friction and axial location effect. 


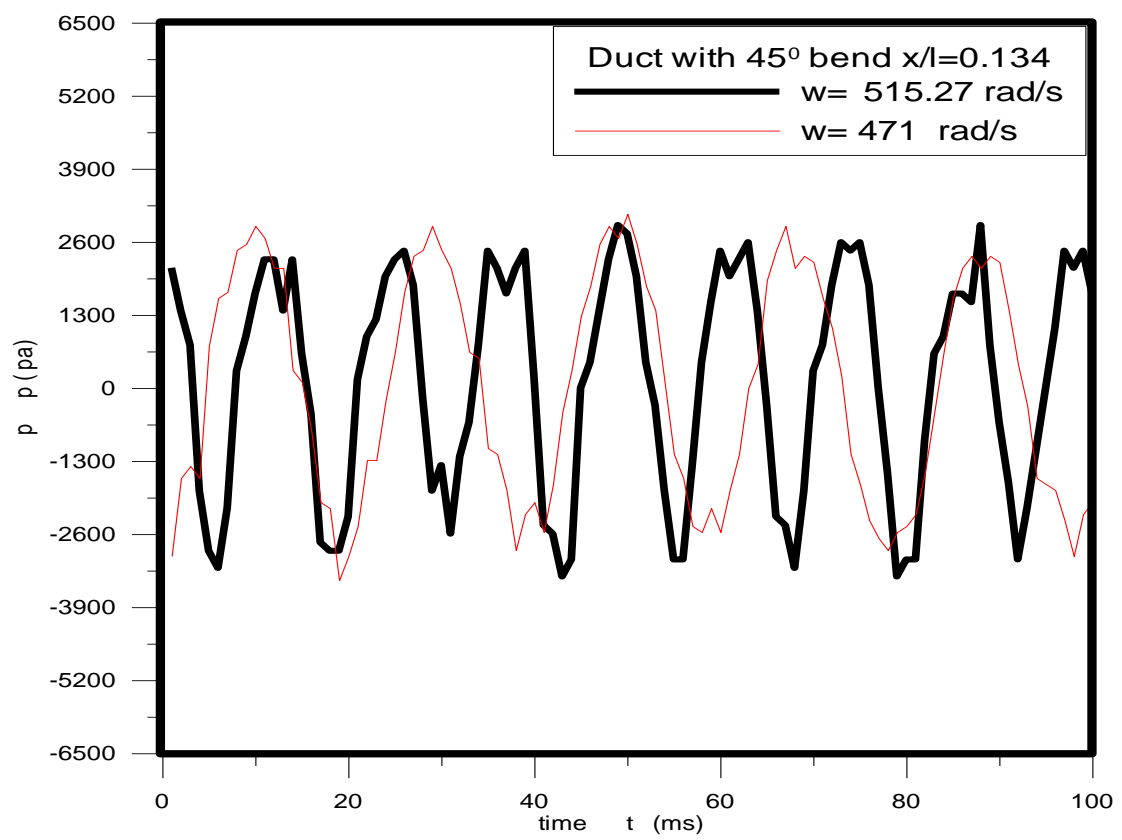

Fig. 10. Dimensional pressure time history for the duct with $45^{\circ}$ bend at $\omega=515.27$ and $471 \mathrm{rad} / \mathrm{s}$ and $X / L=0.134$.

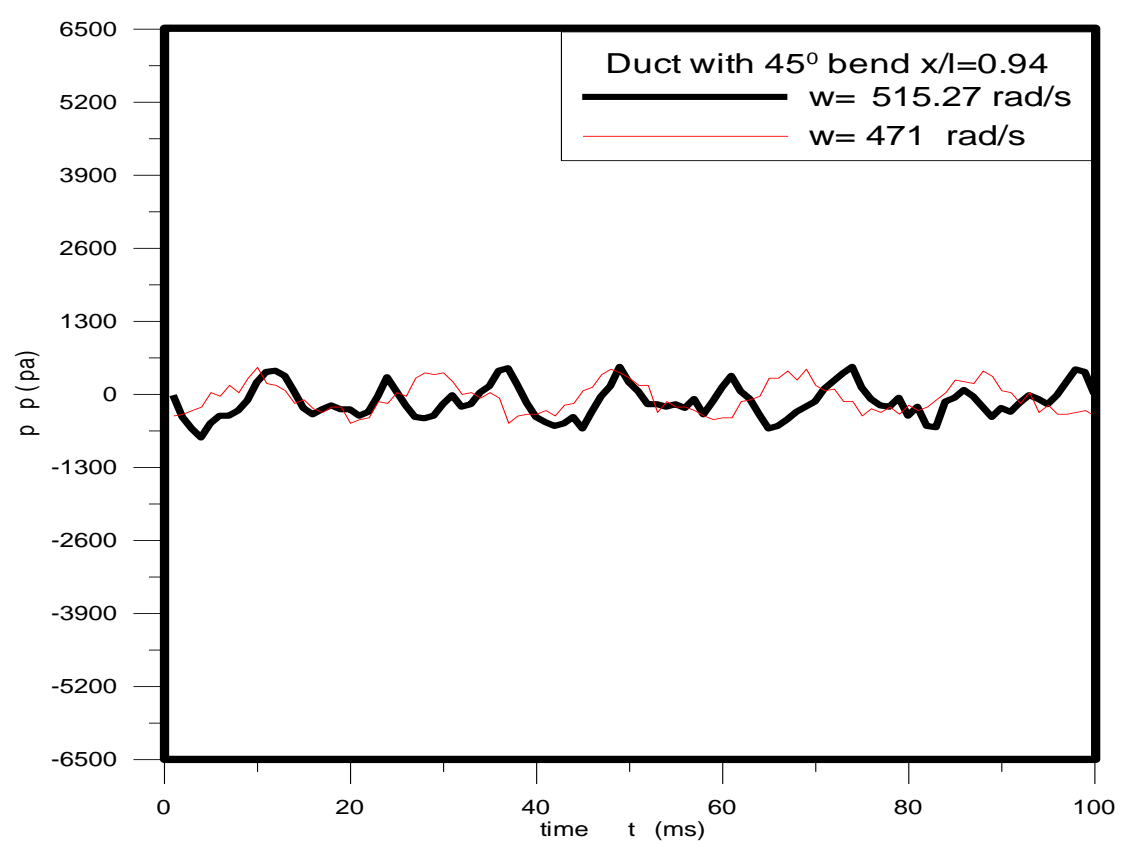

Fig. 11. Dimensional pressure time history for the duct with $45^{\circ}$ bend at $\omega=515.27$ and $471 \mathrm{rad} / \mathrm{s}$, and $X / L=0.941$.

Figure 12 shows the effect of axial location on the pressure time history for the duct with $135^{0}$ bend at the exit. It can been seen from this figure that the pressure amplitude decreases downstream the duct due to the friction losses and open end wave reflection effect. Meanwhile, we can figure out that the acoustic pressure increases closes to the reciprocating piston. The amplitude is not highly effected by the axial location in this case compared to the free end duct. 
Figures 13, 14 and 15 represent the effect of axial location on the generated pressure time history at the three different locations for the free end duct and duct fitted by the three bends. The free end duct shows higher pressure amplitude at the points near the piston and vice versa close to the duct exit. This phenomenon is made by the reflected waves returned in the opposite direction and overlap with the coming waves from the piston which leads to a reduced wave amplitude. Also, the amplitude of the wave at the duct inlet after the piston increases with the raising of the bend turning angle from $45^{\circ}$ to $135^{\circ}$ but the wave amplitude decreases with increasing the bend angle at the duct exit exactly before the bend. That is due to the wave reflections from the bend at the duct exit and wave interaction between different wave phases at the duct exit.

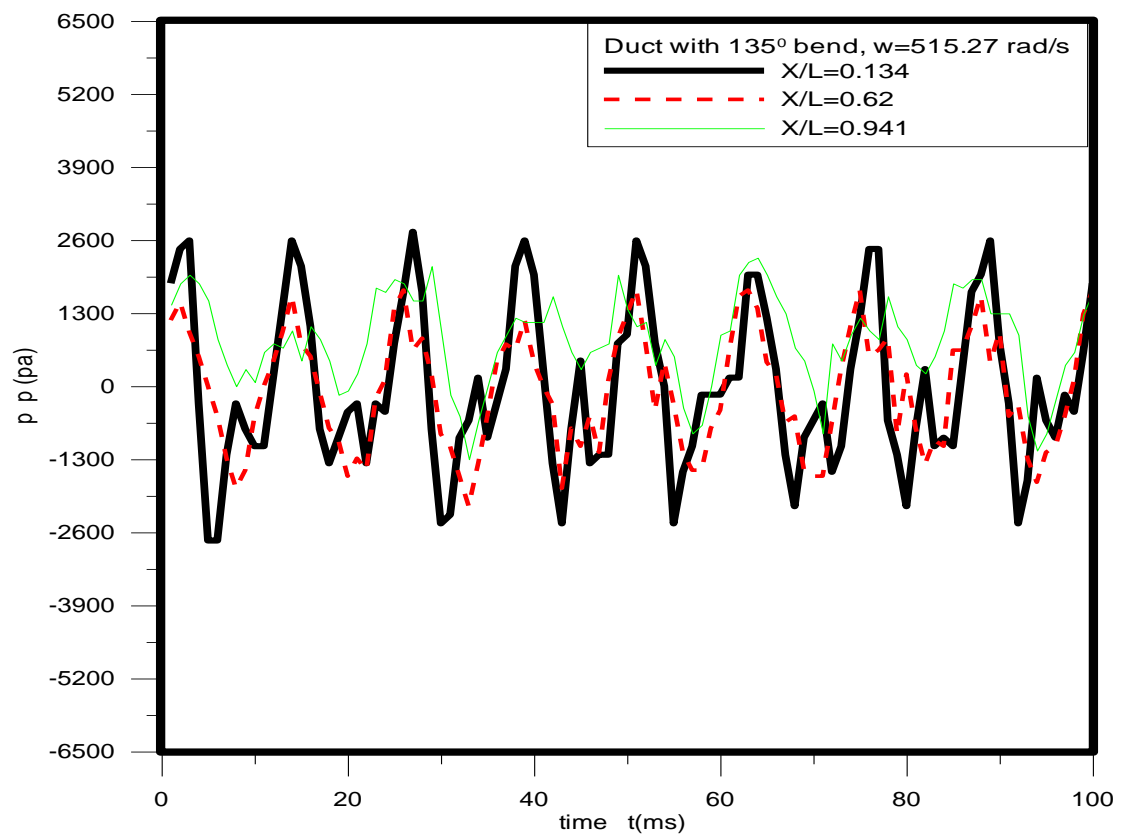

Fig. 12. Dimensional pressure time history at different axial location for the duct with $135^{\circ}$ bend.

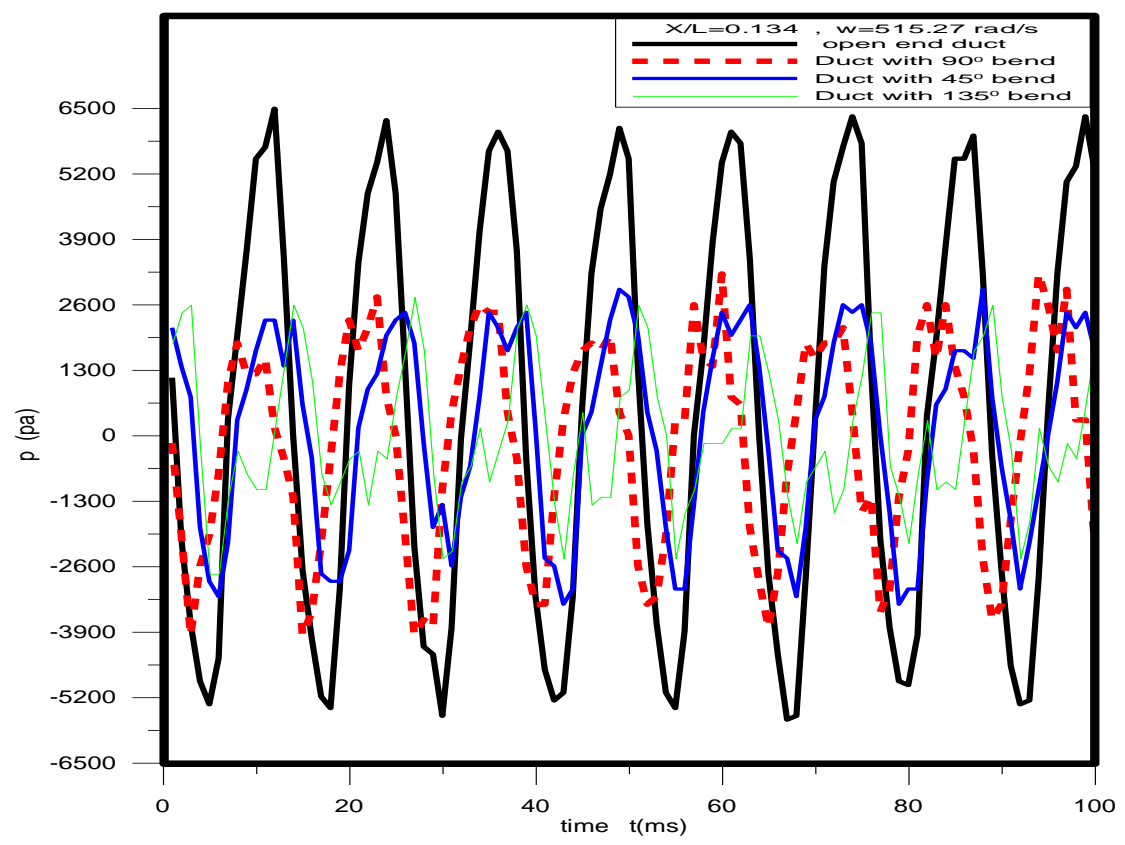

Fig. 13. Comparison between free end duct and duct with the three bend angles of $45^{\circ}, 90^{\circ}$ and $135^{\circ}$ at $X / L=0.134$ and $\omega=515.27 \mathrm{rad} / \mathrm{s}$. 


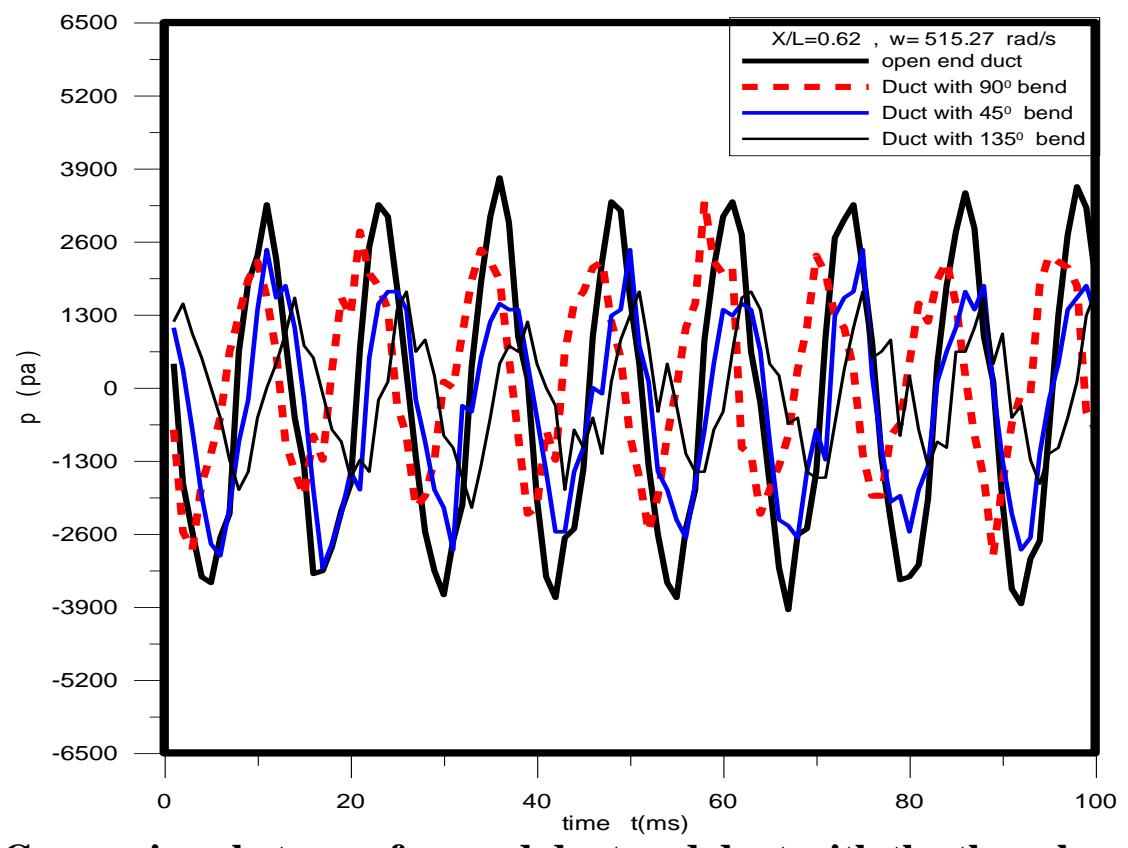

Fig. 14. Comparison between free end duct and duct with the three bend angles of $45^{\circ}, 90^{\circ}$ and $135^{\circ}$ at $X / L=0.62$ and $\omega=515.27 \mathrm{rad} / \mathrm{s}$.

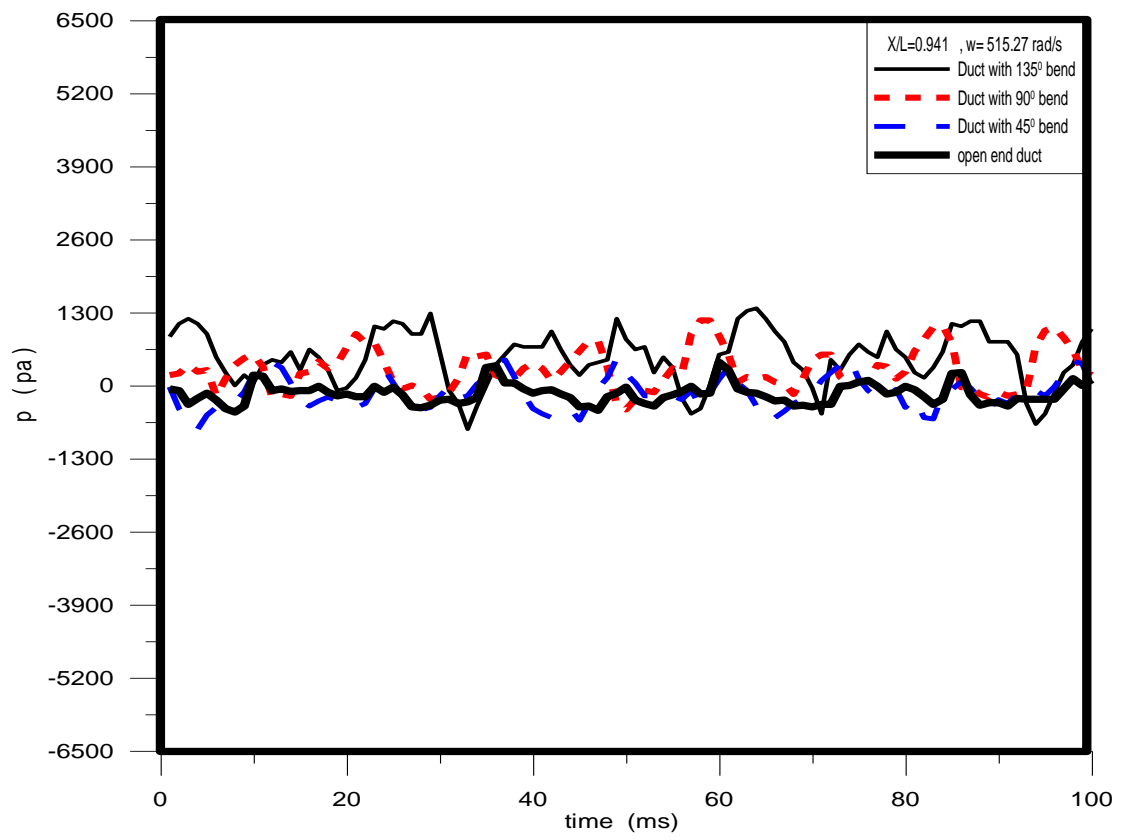

Fig. 15. Comparison between free end duct and duct with the three bend angles of $45^{\circ}, 90^{\circ}$ and $135^{\circ}$ at $X / L=0.941$ and $\omega=515.27 \mathrm{rad} / \mathrm{s}$. 


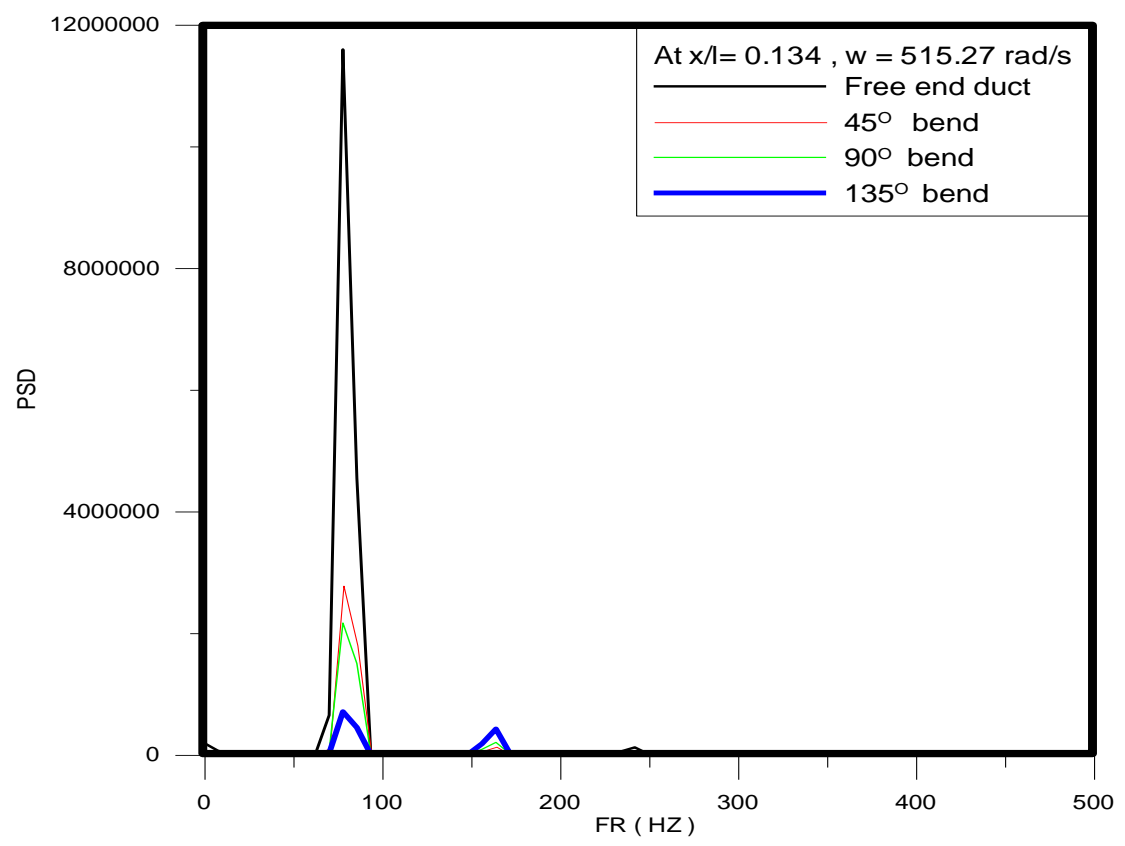

Fig. 16. Power spectrum density for free end duct and duct fitted with bends of $45^{\circ}, 90^{\circ}$ and $135^{\circ}$ at $\mathrm{X} / \mathrm{L}=0.134$ and $\mathrm{w}=515.27 \mathrm{rad} / \mathrm{s}$

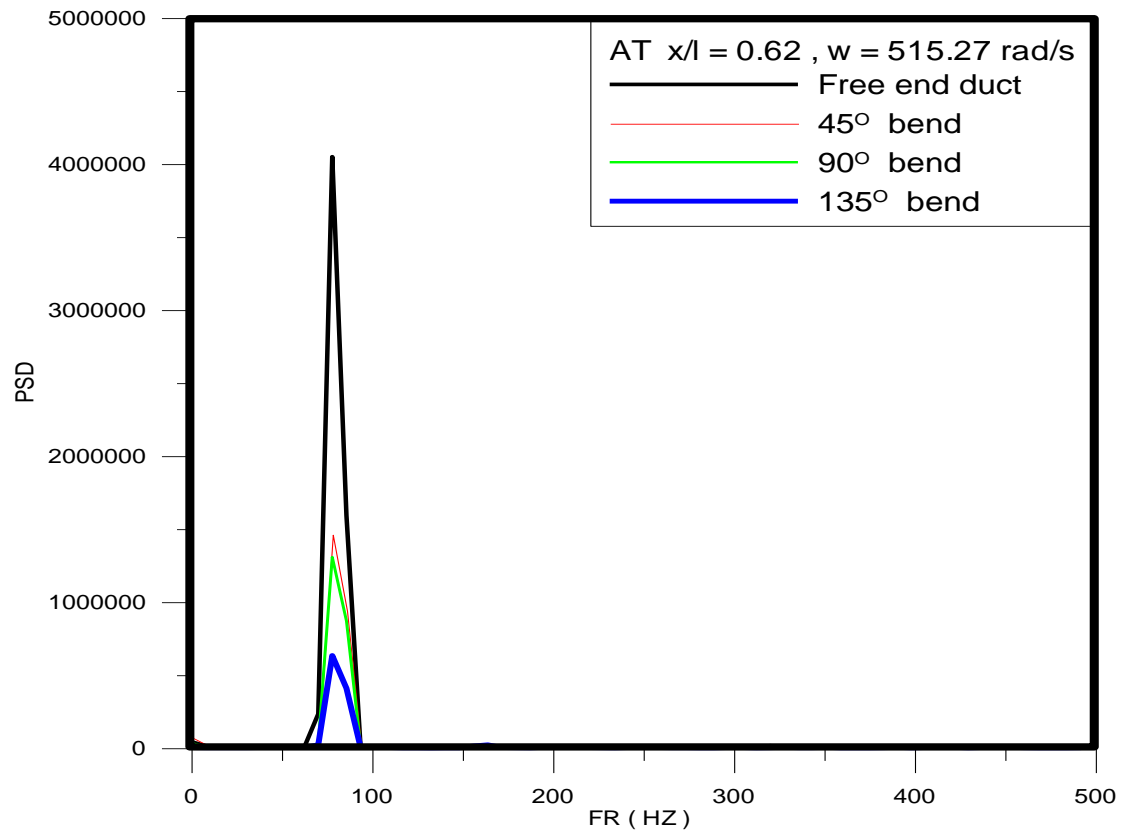

Fig. 17. Power spectrum density for free end duct and duct fitted with bends of $45^{\circ}, 90^{\circ}$ and $135^{\circ}$ at $X / L=0.62$ and $w=515 \mathrm{rad} / \mathrm{s}$ 


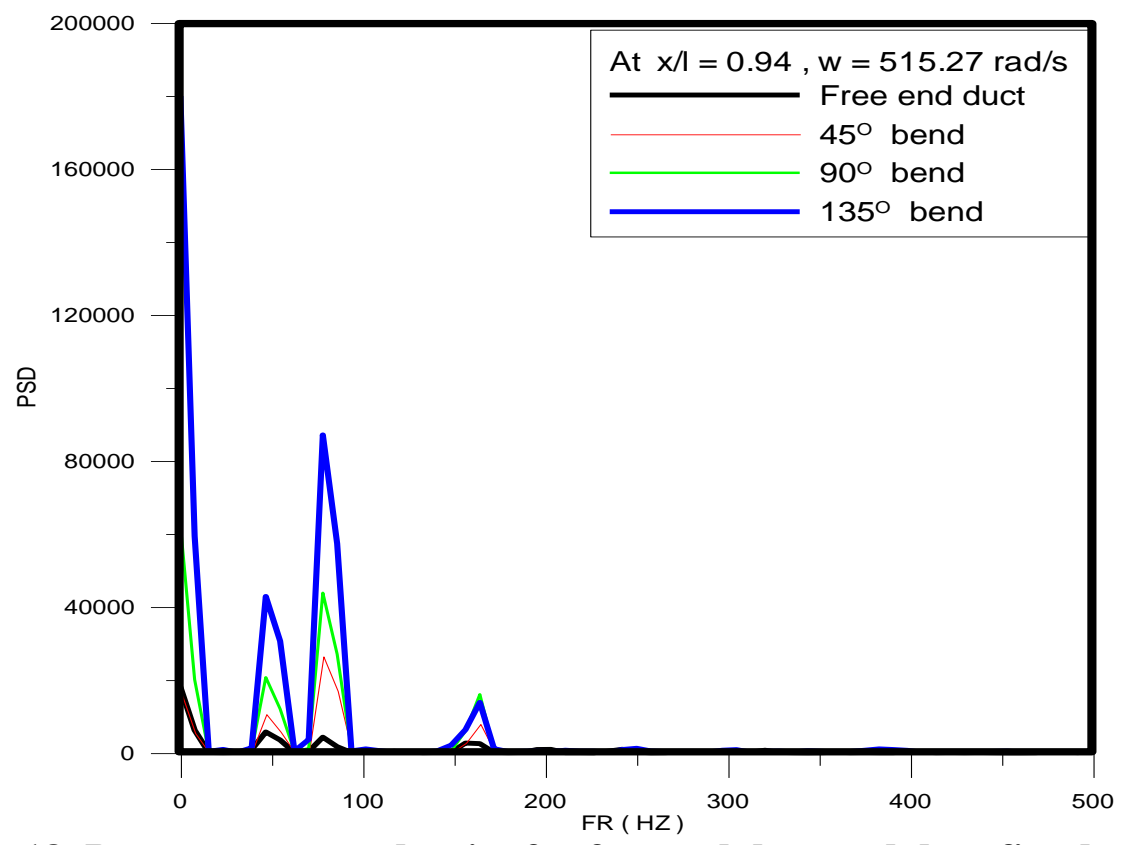

Fig. 18. Power spectrum density for free end duct and duct fitted with bends of $45^{\circ}, 90^{\circ}$ and $135^{\circ}$ at $X / L=0.941$ and $w=515.27 \mathrm{rad} / \mathrm{s}$.

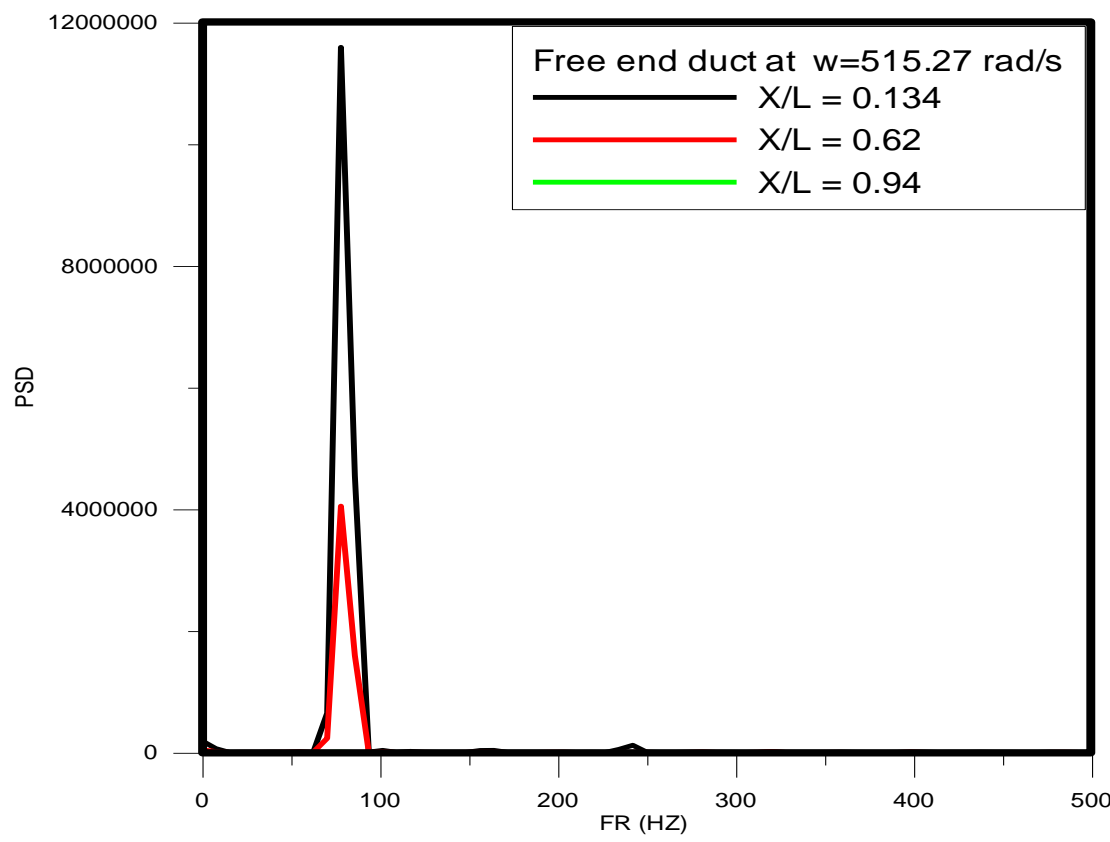

Fig. 19. Power spectrum density for free end duct at $X / L=0.134,0.62$ and 0.94 and $w=515.27 \mathrm{rad} / \mathrm{s}$.

The power spectrum is calculated from the experimental data and is given in Figs. 16 to 21 . The power spectrum density in all figures show that the gas oscillates at the same forcing frequency of the reciprocating piston. Meanwhile, higher harmonics of low energy content could be noticed in case of duct fitted with bends especially close to the duct exit. These higher harmonics can be significantly observed in Figs 16 and 18 for duct fitted with $135^{\circ}$ bend. This indicates the wave steepness behavior at the duct exit and also a lot of interaction between the compression and rarefaction waves can occur. The power spectrum illustrates also that near the duct exit, the energy content of different cases differs slightly, whereas that of free end duct is almost negligible because almost all the wave energy is transmitted out (radiated to the 
atmosphere). However, at $\mathrm{X} / \mathrm{L}=0.134$ no signal of higher harmonics can be shown. One can also notice that a significant high energy content of the wave close to the piston, compared with that near the duct exit. This is likely to occur because the measuring point near the piston is closer to the acoustic energy source. Fig. 21 shows that the energy decreases with lowering the number of revolutions at the measuring point close to the piston.

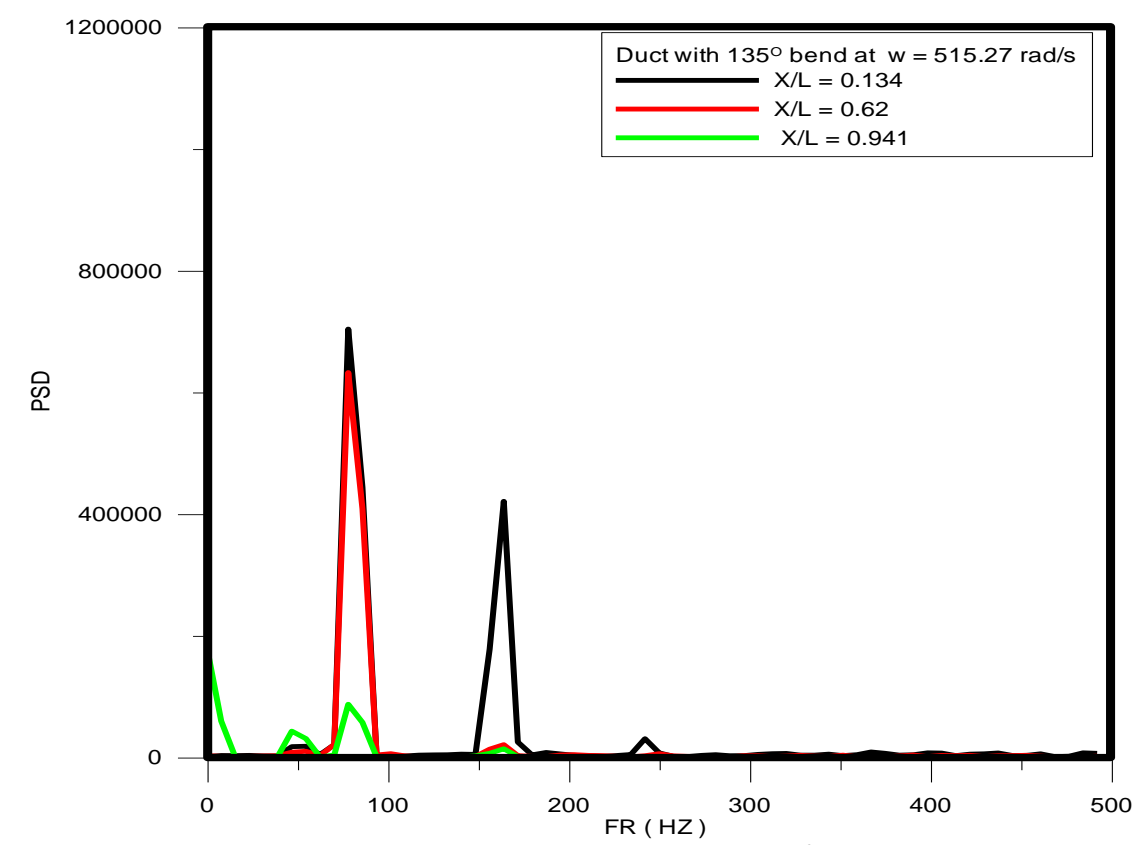

Fig. 20. Power spectrum density for duct with $135^{\circ}$ bend at $X / L=0.134,0.62$ and 0.94 and $w=515.27 \mathrm{rad} / \mathrm{s}$.

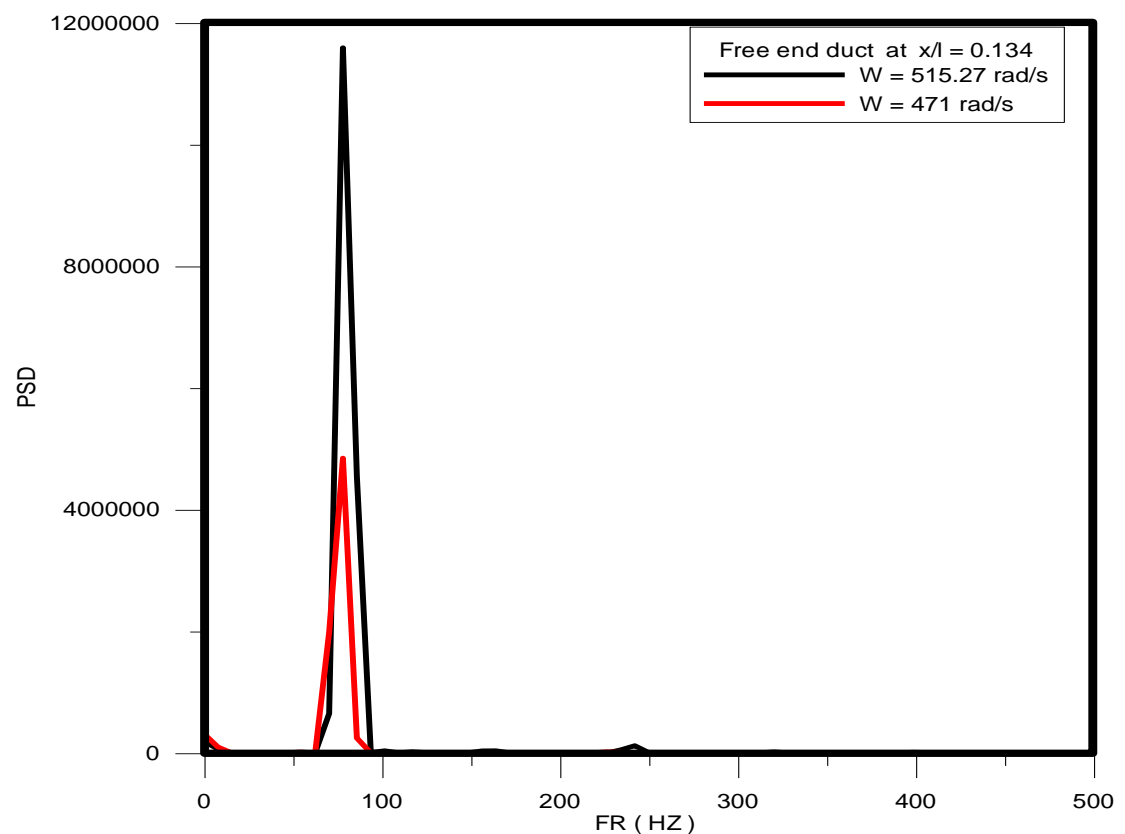

Fig. 21. Power spectrum density for free end duct at $X / L=0.134$ and $\mathrm{w}=\mathbf{5 1 5 . 2 7}$ and $471 \mathrm{rad} / \mathrm{s}$. 


\section{Conclusions}

This paper presents the effect of installing bends with different turning angles on the pressure time history generated inside a circular duct. Comparisons between the numerical, analytical and experimental results have been performed at the same operational conditions and the results show a reasonable agreement. The results show that, the pressure amplitude decreases from the piston downstream the duct for all cases due to friction losses. Also, it is noted that, pressure amplitude decreases with diminishing the bend turning angle close to the piston but it increases with magnifying the bend angle close to the duct exit. That may be attributed to the amount of wave reflected from the open end which interacts with the upcoming waves from the reciprocating piston. Also, it is shown that the pressure amplitude increases with decreasing the bend angle. Raising up the forcing frequency increases the pressure amplitude due to wave amplitude magnifying. Moreover, bend connections fitted at the duct exit raise the existence of higher harmonics compared to the free end duct case.

\section{References}

[1] B. P. Semeniuk," Simple one and Three-Dimensional Finite Element Methods for Low Frequency Duct Acoustics", MSc Thesis, University of Alberta, Canada 1993.

[2] G. Galiullin, E. R. Galiullina, and E. I. Permyakov," Resonant Oscillations of A gas in An open-Ended Tube in A weak Turbulence Regime", Journal of Applied Mechanics and Technical Physics, Vol. 39, No. 3, 1998, pp. 404-410

[3] H. Sohn, H. Lee and G. Park, "A study of the flow characteristics of developing turbulent pulsating flows in a curved duct ", Journal of Mechanical Science and Technology, Vol. 21, No. 12, 2007, pp. 2229-2236.

[4] A. Sileem and M. Nasr," An experimental study on finite amplitude oscillations in ducts: the effect of adding variable area part to the open end of constant-area resonant tube", Alexandria Engineering Journal, Vol. 42, No. 4, 2003, pp. 397-409.

[5] M. Nasr, A. M. Hegab, W. A. El-Askary, K. A. Yousif, " An Investigation on the Internal Flow in Simulated Solid Rocket Motor Chamber/Nozzle Configuration ", $13^{\text {th }}$ International Conference on aerospace and aviation technology, Cairo Egypt, 2009.

[6] Z. Jinsuo and Z. Benzhao, "Fluid Flow in A Helical Pipe", Acta Mechanica Sinica (English Series), Vo1. 15, No. 4, 1999, pp. 299-312.

[7] A. Dequand, S. J. Hulshoff, Y. Auregan, J. Ijnen, L. j. vonling and A. Hirschberg, "Acoustics of 90 Degree Sharp Bends. Part I: Low-frequency Aero Acoustical Response", Acta Acustica united with Acustica, Vol. 90, No. 1, 2004, pp. 13-23.

[8] S. W. Rienstra and A. Hirschberg," An Introduction to Acoustics ", Report, Eindhoven University of Technology Netherlands, 2011.

[9] S. Huang, S. Wang, and W. Li, and , Q. Wang, "Electromagnetic Ultrasonic Guided Waves “, Springer Series in Measurement Science and Technology, 2016, pp.153-181.

[10] C. Uz, and T. T. Ata, "Acoustic Fatigue and Dynamic Behavior of Composite Panels under Acoustic Excitation ", Proceedings of the Society for Experimental Mechanics Series Conference (CPSEMS), Ankara, Turkey, 2016, pp. 219-229.

[11] http://datasheets.globalspec.com /ds/2/OMEGA Engineering/F9474B4C-160D-42B29B02-BA251EE7031C.

[12] https://www.omega.com/manuals/manualpdf/M4259.pdf.

[13] B. E. Launder and D. B. Spalding," Lectures in Mathematical Models of Turbulence", Academic Press, London, England, 1972.

[14] Ansys Fluent 16 theory's guide, 2014. 